\title{
International Journal of Engineering
}

Journa l Ho me pag e: w w w. i je.i r

\section{Designing Exponentially Weighted Moving Average Control Charts under Failure Censoring Reliability Tests}

\author{
P. Mohammadipoura, H. Farughi*a ${ }^{*}$ H. Rasay ${ }^{b}$, J. Arkat $^{\mathrm{a}}$ \\ ${ }^{a}$ Department of Industrial Engineering, University of Kurdistan, Sanandaj, Iran \\ ${ }^{b}$ Department of Industrial Engineering, Kermanshah University of Technology, Kermanshah, Iran
}

\section{$P A P E R \quad I N F O$}

\section{Paper history:}

Received 22 June 2021

Received in revised form 15 August 2021

Accepted 16 August 2021

\section{Keywords:}

Control Chart

Statistical Process Control

Lifetime Testing

Failure Censoring

Quality Characteristic

Average Run Length

\section{$A B S T R$ A $C$ T}

One of the most important quality characteristics in a production process is the product lifetime. The production of highly reliable products is a concern of manufacturers. Since it is time-consuming and costly to measure lifetime data, designing a control chart seems difficult. To solve the problem, lifetime tests are employed. In the present study, one-sided and two-sided exponentially weighted moving average (EWMA) control charts are designed under a type II censoring (failure censoring) life test. Product lifetime is a quality characteristic dealt with in this study. It is assumed to follow the Weibull distribution with a fixed shape parameter and a variable scale parameter. In order to design a control chart, first, the control chart limits are calculated for different parameters, and then the Average Run Length (ARL) in the out-of-control state is used to evaluate the performance of the proposed control chart. Next, a comprehensive sensitivity analysis is performed for the different parameters involved. The computational results show that the one-sided control chart has better performance to detect the shift of lifetime data than the two-sided control chart. The average run length curve of the two-sided control chart is biased, while that of the one-sided control chart is unbiased. A very effective parameter that increases the performance of a control chart is found to be the number of failures in the failure censoring process. Finally, simulated and real examples are provided to show the performance of the proposed control chart.

doi: $10.5829 /$ ije.2021.34.11b.03

\begin{tabular}{llll}
\hline NOMENCLATURE & & \\
\hline$m$ & Shape parameter & UCL & Upper control limit \\
$\theta$ & Scale parameter & LCL & Lower control limit \\
$c$ & Shift constant & $\alpha$ & Probability of type I errors for the control chart \\
$r$ & Number of failures & $\beta$ & Probability of type II errors for the control chart \\
$n$ & Sample size in the life test & ARL0 & In-control average run length \\
$V(i)$ & Statistic of the life test censoring & ARL1 & Out-of-control average run length \\
$Q(i)$ & Statistic of the EWMA chart & $\lambda$ & Smoothing constant in the EWMA chart \\
$\Gamma$ & Gamma function & $\phi$ & Cumulative distribution function of the normal distribution \\
\hline
\end{tabular}

\section{INTRODUCTION ${ }^{1}$}

Nowadays, many products of different brands are introduced in markets, but consumers consistently demand only a small number of them due to their quality characteristics [1]. In this regard, statistical process control (SPC) is widely used as a method of statistical quality control (SQC). As a very powerful tool for monitoring a process in SPC, a control chart is used mainly to maintain the statistical stability of the process. A control chart has a center-line (CL) and two control limits, including the lower control limit (LCL) and the upper control limit (UCL) [2]. Based on the sample statistics, the process status is divided into in-control and out-of-control states. If the drawn points are between the LCL and the UCL, the process is assumed to be in control; otherwise, it is assumed to be out of control [3].

\footnotetext{
* Corresponding Author's Email: h.farughi@uok.ac.ir (H. Farughi)
} 
A serious weakness of the control charts designed by Shewhart is in the use of the information of the last sample rather than that of the old samples. Unlike Shewhart control charts, memory-type control charts use the information of both the old and the previous samples. So, if the goal is to detect small changes in a process, it is a memory-type control chart to use. Another popular and widely-used memory-type control chart is the EWMA control chart, first introduced by Roberts [4] in 1959.

To design a control chart for process monitoring, there is a need for enough data about the quality characteristics to be examined. However, collecting enough data for this purpose is not practical in some industries or processes. The problem is attributed to product lifetime as an important quality characteristic; data collection is difficult, time-consuming, and costly. In this case, reliability lifetime tests are used to obtain the required data on lifetime [5].

The application of control charts is now widespread in various fields of engineering, management, services, biology, healthcare, and finance. Kabiri and Bayati [6] used control charts as important tools of statistical process control in combination with modern tools such as artificial neural networks. Fattahzadeh and Saghaei [7] monitored their processes using image sensors and control charts. Rasay et al. [8] showed the application of multivariate control charts in condition-based maintenance. Sadeghi et al. [9] proposed a control method based on Shewhart control charts to monitor financial processes.

In general, the research performed so far has been on the type of control charts and life tests in various distributions. For example, a Shewhart variable control chart was designed by Khan et al. [10] through failure censoring, assuming that lifetime follows the Weibull distribution with a fixed shape parameter and a variable scale parameter. Adebayo and Ogundipe [11] assumed that product lifetime follows a generalized exponential distribution with a fixed shape parameter and a variable scale parameter. They then designed an attribute control chart using truncated life tests. Balamurali and Jeyadurga [12] designed an attribute NP control chart to monitor the mean lifetime of type-II Pareto distribution through truncated life tests and multiple deferred state sampling.

Aslam et al. [13] presented a mixed control chart through the accelerated hybrid censoring that monitors variable and attribute quality characteristics. Rao et al. [14] designed an attribute NP control chart via truncated life tests and assumed that the product lifetime follows a Dagmu distribution with a fixed shape parameter and a variable scale parameter.

$\mathrm{Xu}$ and Daniel [15] presented a WEWMA chart to monitor lifetime with the Weibull distribution using type I censored data. In the research by Faraz et al. [16], the shape and scale parameters of the Weibull distribution were assumed to be unknown, and then the control charts of $S^{2}$ and $\bar{Z}$ were proposed to monitor the shifts in the shape and scale parameter of the Weibull distribution. One-sided and two-sided t-control charts were presented by Rasay and Arshad [17] using a failure censoring test to monitor lifetime when it followed exponential distribution. Table 1 summarizes the most relevant studies in this area.

A literature review shows that the design of control charts with life tests and monitoring lifetime data is of great importance. In addition, most of the studies conducted in this area are related to two-sided control charts; there has been only a little research on designing one-sided control charts and memory-based control charts. To the best of the authors' knowledge, no research has been conducted on designing one-sided EWMA control charts using failure censoring life tests.

Hence, in the present study, the one-sided and twosided EWMA control charts are designed through a Type II censoring life test to monitor the average lifetime of the Weibull distribution. For this purpose, first, the relationships among one-sided and two-sided control limits, type II error, and the average run length in the outof-control state are identified. Then, the performance of the control chart is evaluated by ARL in the out-ofcontrol mode. Finally, a comprehensive sensitivity analysis is performed based on the problem parameters.

TABLE 1. Research summary

\begin{tabular}{|c|c|c|c|c|}
\hline $\begin{array}{l}\text { Lifetime } \\
\text { distribution }\end{array}$ & Life test & $\begin{array}{c}\text { Control } \\
\text { chart }\end{array}$ & Year & Author \\
\hline Weibull & $\begin{array}{c}\text { failure } \\
\text { censoring }\end{array}$ & $\begin{array}{c}\text { Variable } \\
\text { control chart }\end{array}$ & 2018 & $\begin{array}{c}\text { Nasrullah } \\
\text { Khan et al. } \\
\text { [10] }\end{array}$ \\
\hline Weibull & $\begin{array}{l}\text { Truncated } \\
\text { life test }\end{array}$ & $\mathrm{np}$ & 2018 & $\begin{array}{c}\text { Balamurali } \\
\text { \& Jeyadurga } \\
{[12]}\end{array}$ \\
\hline Weibull & - & $\begin{array}{c}\text { Shewhart } \\
\text { control chart } \\
(\overline{\mathrm{X}} \text { and } \mathrm{s})\end{array}$ & 2014 & $\begin{array}{c}\text { Faraz et al. } \\
{[16]}\end{array}$ \\
\hline $\begin{array}{l}\text { Generalized } \\
\text { Exponential }\end{array}$ & $\begin{array}{l}\text { Trancated } \\
\text { life test }\end{array}$ & $\mathrm{np}$ & 2020 & $\begin{array}{c}\text { Adebayo \& } \\
\text { Ogundipe } \\
{[11]}\end{array}$ \\
\hline Weibull & $\begin{array}{l}\text { hybrid } \\
\text { censoring } \\
\text { life test }\end{array}$ & $\begin{array}{l}\text { Mixed control } \\
\text { chart }\end{array}$ & 2020 & $\begin{array}{c}\text { Muhammad } \\
\text { Aslam et al. } \\
{[13]}\end{array}$ \\
\hline $\begin{array}{l}\text { Pareto } \\
\text { distribution of } \\
\text { the second } \\
\text { kind }\end{array}$ & $\begin{array}{c}\text { Truncated } \\
\text { life test }\end{array}$ & $\mathrm{np}$ & 2019 & $\begin{array}{c}\text { Balamurali } \\
\text { \& Jeyadurga } \\
{[12]}\end{array}$ \\
\hline Dagmu & $\begin{array}{c}\text { Trancated } \\
\text { life test }\end{array}$ & $\mathrm{np}$ & 2019 & $\begin{array}{c}\text { Rao et al. } \\
{[14]}\end{array}$ \\
\hline Exponential & $\begin{array}{c}\text { failure } \\
\text { censoring }\end{array}$ & t control chart & 2020 & $\begin{array}{c}\text { Rasay \& } \\
\text { Arshad [17] }\end{array}$ \\
\hline Weibull & $\begin{array}{c}\text { type I } \\
\text { censored }\end{array}$ & $\begin{array}{l}\text { WEWMA } \\
\text { chart }\end{array}$ & 2018 & $\begin{array}{c}\text { Xu \& Daniel } \\
{[15]}\end{array}$ \\
\hline
\end{tabular}


The rest of the paper is organized into several sections. First, the problem for which the control charts are designed is described. The next section discusses how to design one-sided and two-sided control charts. Section 4 is devoted to the computation of the average run length of the control charts. In section 5, several simulated examples are presented. Using simulation studies, a case study is presented in section 6. Finally, section 7 concludes the paper.

\section{DESCRIPTIONS}

Consider the lifetime of an item, which is denoted by X, as its concerned quality characteristic. In the current study, it is assumed that $\mathrm{X}$ follows the Weibull distribution with the following cumulative distribution function:

$$
F_{x}(x)=1-\exp \left[-(x \theta)^{m}\right]
$$

In Equation (1), $\theta$ and $m$ are the scale and the shape parameters of the distribution, respectively. The mean lifetime of the Weibull distribution has the following form:

$$
\mu=\frac{\Gamma\left(\frac{1}{m}\right)}{\theta m}
$$

In Equation (2), it is supposed that variable $m$ has a stable shape parameter, but the scale parameter needs to be monitored using a suitable control chart. In the following section, some control charts are proposed for this purpose.

It is to be noted that the distribution of the data on lifetime is determined according to historical data and by statistical tests such as the goodness of fit test. Lifetime is one of the characteristics that often follow non-normal distributions; a normal distribution has limited application in longevity data. Weibull, exponential, normal log, gamma, and Pareto distributions are the most important distributions used to model quality characteristics in reliability.

To monitor the scale parameter of the Weibull distributed items, a failure censoring reliability test is conducted. More specifically, first, $\mathrm{n}$ items are randomly selected and put on the test simultaneously. The test continues until $r$ failures $(r \leq n)$ are observed. During the test, the failure time of each item is recorded to obtain $x_{(1)}, x_{(2)}, \ldots, x_{(r)}$ as the order statistic data. Accordingly, the following statistic is computed:

$$
V_{i}=\sum_{i=1}^{r}\left(\frac{x_{i}}{\mu_{0}}\right)^{m}+(n-r)\left(\frac{x_{r}}{\mu_{0}}\right)^{m}
$$

where $\mu_{0}$ is the specified mean time and $x_{i}$ is the failure time of the i'th item.

According to Jun et al. [18], $V_{i}$ follows a gamma distribution with parameters $\mathrm{W} 0$ and $\mathrm{r}$. $\mathrm{W}_{0}$ is computed as follows:

$$
W_{0}=\left(\theta_{0} \mu_{0}\right)^{m}=\left(\frac{\Gamma(1 / m)}{m}\right)^{m}
$$

According to Jun et al. [18], $2 \mathrm{VW}_{0}$ follows a chisquare distribution with $2 \mathrm{r}$ degrees of freedom.

It is desirable to monitor the scale parameter $\theta$, or the alternative process mean $\mu$, using an appropriate control chart. As it is known, indeed, at each sampling point, there is a statistical hypothesis test to conduct. Let's assume $\theta_{0}$ and $\mu_{0}$ as the target values of the scale parameter and the mean, respectively. In this regard, the following hypothesis tests are conducted:

$$
\mathrm{A}:\left\{\begin{array}{l}
H_{0}: \mu=\mu_{0} \\
H_{0}: \mu>\mu_{0}
\end{array} \quad, \quad \mathrm{~B}:\left\{\begin{array}{l}
H_{0}: \mu=\mu_{0} \\
H_{0}: \mu \neq \mu_{0}
\end{array}\right.\right.
$$

Hypothesis test A leads to a one-sided control chart, while B leads to a two-sided control chart.

\section{DESIGNING THE CONTROL CHARTS}

In this section, first, the design of a one-sided control chart is discussed, and then a two-sided control chart is presented.

As $2 V W_{0}$ follows a chi-square distribution with $2 \mathrm{r}$ degrees of freedom, the following equations can be obtained for the mean and the variance of $V_{i}$ :

$$
\begin{aligned}
& E\left(V_{i}\right)=\frac{r}{w_{0}} \\
& \operatorname{var}\left(V_{i}\right)=\frac{r}{w_{0}^{2}}
\end{aligned}
$$

At the i'th sampling time, the following EWMA statistic is computed and plotted on an EWMA control chart:

$$
Q_{i}=\lambda V_{i}+(1-\lambda) Q_{i-1}
$$

where $\lambda$ is the smoothing parameter of the EWMA control chart.

The central limit theorem is used to obtain the control limits of the EWMA chart. According to theorem, if the variables $x_{1}, x_{2}, x_{3}, \ldots, x_{n}$ are independent of one another, it can be concluded that the sum or mean of $\mathrm{x}_{\mathrm{i}}$ follows a normal distribution for large 'i's. Now, the values are inserted in Equation (7) instead of all $Q_{i-1}$, and the following equation is obtained:

$$
Q_{i}=\lambda \sum_{j=0}^{i-1}(1-\lambda)^{j} V_{i-j}+(1-\lambda)^{i} Q_{0}
$$

Based on Equation (8), the values of $Q_{i}$ depend only on the initial value of $Q_{0}$ and the values of $V_{i}$. Therefore, $Q_{i}$ values will be independent of each other. According to the central limit theorem, it can be concluded that the mean and variance of $Q_{i}$ for a large value of I are as follows:

$$
E\left(Q_{i}\right)=E\left(V_{i}\right)=\frac{r}{w_{0}}
$$




$$
\operatorname{Var}\left(Q_{i}\right)=\operatorname{Var}\left(V_{i}\right) \times\left(\frac{\lambda}{2-\lambda}\right)=\frac{r}{w_{0}^{2}} \times \frac{\lambda}{2-\lambda}
$$

In the following, the relationships of control limits, $\beta$ error and $\mathrm{ARL}_{1}$ are presented for one-sided and two-sided EWMA control charts.

\section{1. One-sided Control Chart}

Suppose that a process is only concerned with monitoring the deterioration of quality characteristic. In this case, onesided control charts are used with LCL.

The Equation of LCL, based on the results of the central limit theorem and the mean and variance of $Q_{i}$, is as follows:

$$
\begin{aligned}
& L C L=\mu_{Q_{i}}-k \sigma_{Q_{i}} \\
& =\frac{r}{W_{0}}-Z_{\alpha}\left(\frac{\lambda}{2-\lambda} \times \frac{r}{w_{0}^{2}}\right)^{0.5}
\end{aligned}
$$

where $\mathrm{k}$ is the coefficient of control limits, which is considered equal to $Z_{\alpha}$, and $Z_{\alpha}$ is a certain percentage of the distribution $N(0,1)$. So, $\mathrm{P}\left\{\mathrm{Z} \geq \mathrm{Z}_{\alpha}\right\}=\alpha$.

\section{2. Two-sided Control Chart The one-sided} control chart cannot show the improvement of the process. To monitor both the improvement and the deterioration of the process, a two-sided control chart is used. Like in most two-sided control charts, let's assume type I error is equally divided for both sides of the control chart.

The control limits of a two-sided control chart are as follows:

$$
\begin{aligned}
& U C L=\mu_{Q_{i}}+k \sigma_{Q_{i}}=\frac{r}{W_{0}}+Z \alpha / 2\left(\frac{\lambda}{2-\lambda} \times \frac{r}{W_{0}^{2}}\right)^{0.5} \\
& L C L=\mu_{Q_{i}}-k \sigma_{Q_{i}}=\frac{r}{W_{0}}-Z \alpha / 2\left(\frac{\lambda}{2-\lambda} \times \frac{r}{W_{0}^{2}}\right)^{0.5}
\end{aligned}
$$

Equations (12) and (13) serve to calculate the values of LCL and UCL, respectively. If a point falls between the two limits, it means that the process is probably incontrol. On the other hand, the occurrence of a point below the LCL can be a sign of the process deterioration, while its being above the UCL is suggestive of the process improvement. With a flowchart, Figure 1 shows the stages of the proposed control chart.

\section{COMPUTING THE ARL OF THE CONTROL CHARTS}

An important indicator of the performance of a control chart is the Average Run Length (ARL). Every control chart has two ARLs; one corresponds to the in-control state $\left(\mathrm{ARL}_{0}\right)$, and the other to the out-of-control state $\left(\mathrm{ARL}_{1}\right)$.

The value of $\mathrm{ARL}_{0}$ is the inverse of type I error; that is, $\mathrm{ARL}_{0}=1 / \alpha$. The value of $\mathrm{ARL}_{1}$, however, depends on the values of the shift and the other characteristics of the control chart.

Let's consider a case in which the scale parameter of the distribution shifts from $\theta_{0}$ to $c \theta_{0}$ and value $c$ determines the magnitude of the shift. For a one-sided control chart, $\beta$ can be obtained as follows:

$$
\begin{aligned}
& \beta=P\left(Q_{i}>L C L \mid \theta_{1}=c \theta_{0}\right)=1- \\
& \phi\left(L C L-\frac{r}{w_{1}} / \sqrt{\frac{\lambda}{2-\lambda} \times \frac{r}{w_{1}^{2}}}\right)
\end{aligned}
$$

Similarly, for a two-sided control chart, $\beta$ is calculated as follows:

$$
\begin{aligned}
& \beta=P\left(L C L<Q_{i}<U C L \mid \theta_{1}=c \theta_{0}\right)= \\
& \phi\left(\frac{U C L-\frac{r}{W_{1}}}{\sqrt{\frac{\lambda}{2-\lambda} \times \frac{r}{W_{1}^{2}}}}\right)-\phi\left(\frac{L C L-\frac{r}{W_{1}}}{\sqrt{\frac{\lambda}{2-\lambda} \times \frac{r}{W_{1}^{2}}}}\right)
\end{aligned}
$$

To obtain the $\mathrm{ARL}_{1}$ values, first, the $\beta$ values are obtained, and then the values of $\mathrm{ARL}_{1}$ are calculated with Equation (16).

$$
A R L_{1}=\frac{1}{1-\beta}
$$

For example, the values of ARL1 for a two-sided control chart are given in Table 2. The following results can be inferred from comparing the tables together and examining the trend of $\mathrm{ARL}_{1}$ shifts for different parameters.

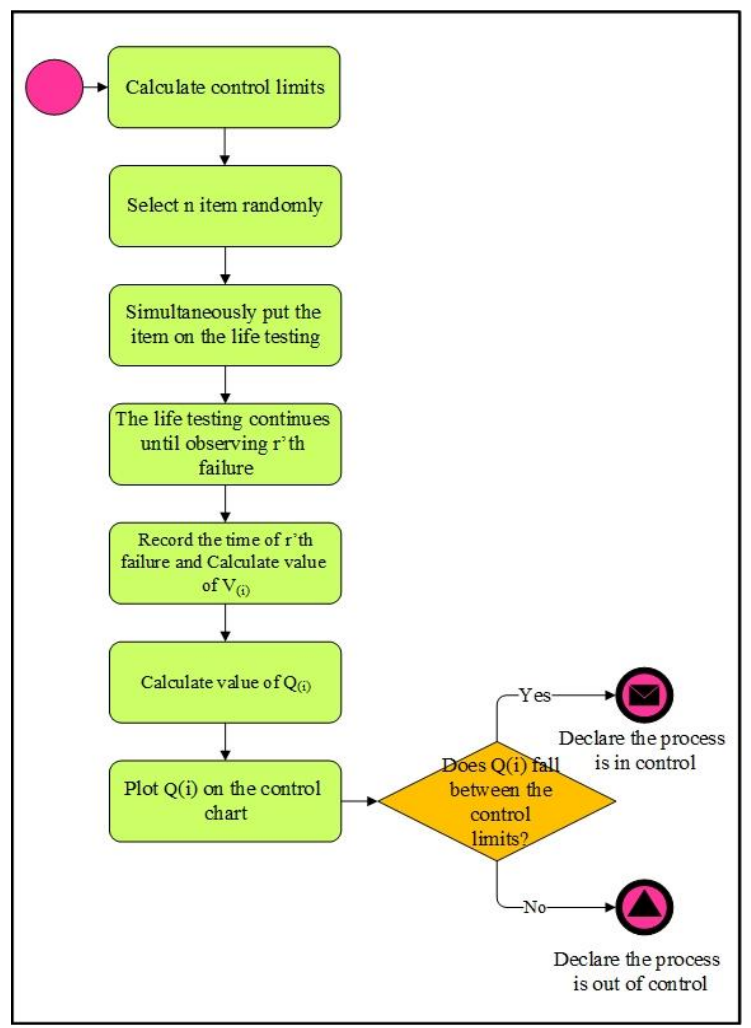

Figure 1. The flowchart of the proposed control chart 
TABLE 2. The ARL for a two-sided control chart

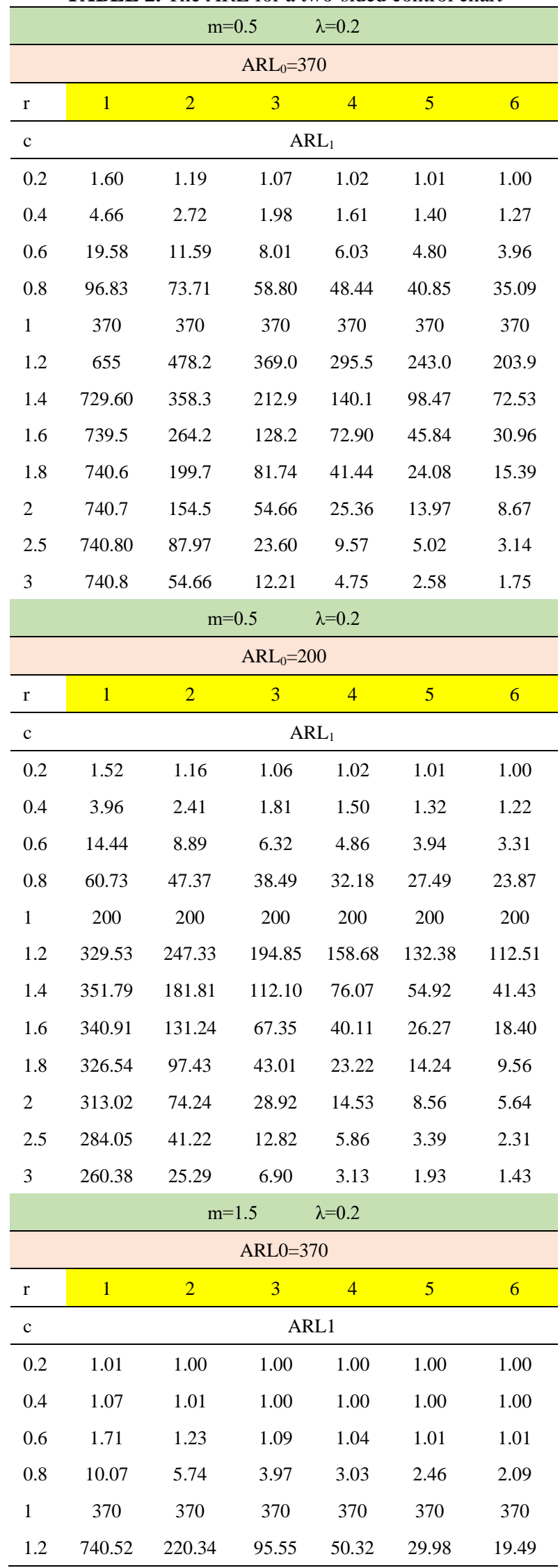

\begin{tabular}{lcccccc}
\hline 1.4 & 740.80 & 69.09 & 16.78 & 6.61 & 3.50 & 2.26 \\
1.6 & 740.80 & 23.80 & 4.42 & 1.89 & 1.27 & 1.08 \\
1.8 & 740.80 & 9.33 & 1.84 & 1.12 & 1.01 & 1.00 \\
2 & 740.80 & 4.29 & 1.18 & 1.01 & 1.00 & 1.00 \\
2.5 & 740.80 & 1.34 & 1.00 & 1.00 & 1.00 & 1.00 \\
3 & 740.80 & 1.01 & 1.00 & 1.00 & 1.00 & 1.00 \\
& \multicolumn{7}{c}{$\mathrm{m}=1.5$} & $\lambda=0.2$ & & \\
\hline & \multicolumn{7}{c}{ ARL0=200 } \\
\hline $\mathrm{r}$ & 1 & 2 & 3 & 4 & 5 & 6 \\
\hline $\mathrm{c}$ & \multicolumn{7}{c}{ ARL1 } \\
\hline 0.2 & 1.01 & 1.00 & 1.00 & 1.00 & 1.00 & 1.00 \\
0.4 & 1.07 & 1.01 & 1.00 & 1.00 & 1.00 & 1.00 \\
0.6 & 1.61 & 1.20 & 1.08 & 1.03 & 1.01 & 1.00 \\
0.8 & 7.93 & 4.72 & 3.35 & 2.62 & 2.17 & 1.88 \\
1 & 200 & 200 & 200 & 200 & 200 & 200 \\
1.2 & 331.67 & 108.11 & 50.22 & 28.00 & 17.53 & 11.90 \\
1.4 & 271.94 & 32.13 & 9.28 & 4.19 & 2.48 & 1.76 \\
1.6 & 220.55 & 11.04 & 2.78 & 1.47 & 1.13 & 1.03 \\
1.8 & 177.35 & 4.57 & 1.40 & 1.05 & 1.00 & 1.00 \\
2 & 141.65 & 2.34 & 1.06 & 1.00 & 1.00 & 1.00 \\
2.5 & 79.14 & 1.08 & 1.00 & 1.00 & 1.00 & 1.00 \\
3 & 43.68 & 1.00 & 1.00 & 1.00 & 1.00 & 1.00 \\
\hline & \multicolumn{7}{c}{00} \\
\hline
\end{tabular}

According to Figure 2, with an increase in the value of $r$, the values of $\mathrm{ARL}_{1}$ decrease. This is because the higher the number of failures in a process, the longer the test time, and the greater the chance of detecting a shift. Therefore, the probability of $\beta$ error and the value of $\mathrm{ARL}_{1}$ are reduced.

According to Figure 3, the value of $\mathrm{ARL}_{1}$ increases as the value of $\mathrm{ARL}_{0}$ rises. Also, as the value of $\mathrm{ARL}_{0}$ increases, the control limits become wider. This means that if a shift occurs in the process, the delay of the chart to detect the shift increases.

According to Figure 4, the value of $\mathrm{ARL}_{1}$ decreases with an increase in the value of $m$. Indeed, an increase in the value of $m$ decreases the probability of $\beta$ error; consequently, $\mathrm{ARL}_{1}$ decreases too.

According to Figure 5, $\mathrm{ARL}_{1}$ value decreases with an increase in the value of $c$. The larger the shift constant in a process, the larger the shift, and the sooner the shift is detected by the chart. Therefore, the probability of $\beta$ error and $\mathrm{ARL}_{1}$ is reduced. In addition, referring to the charts presented, it is quite clear that the $\mathrm{ARL}_{1}$ chart is asymmetric. The values of $\mathrm{ARL}_{1}$ for $\mathrm{c}>1$ are greater than those for $\mathrm{c}<1$. So, the chart can detect $\mathrm{c}<1$ shifts faster.

According to Figure 6, the value of $\mathrm{ARL}_{1}$ increases as the value of $\lambda$ rises. This is because the distance 
between the control limits increases when $\lambda$ rises; therefore, the chance of detecting shifts in the process decreases.

As Figure 7 suggests, an increase in the value of $\alpha$ causes a decrease in the values of $\mathrm{ARL}_{1}$ decrease, which is because the increase of $\alpha$ decreases the probability of $\beta$ error and, consequently, $\mathrm{ARL}_{1}$.

The best performance of a control chart is achieved when $\mathrm{ARL}_{1}$ has its maximum value, $\mathrm{ARL}_{0}$, when the process is in control, i.e., $\mathrm{c}=1$. The $\mathrm{ARL}_{1}$ value decreases as soon as a shift occurs in the process. In the EWMA control chart, the $\mathrm{ARL}_{1}$ chart is biased in some cases; that is, in some cases and for some parameter values, the maximum amount of $\mathrm{ARL}_{1}$ does not occur at $c=1$, as shown in the charts and tables. The $r$ parameter is one of the most important factors that increase the ability of the control chart to detect deviations. This increase greatly improves the chart performance. In other words, as $r$ increases, the biased ARL curve problem is relieved.

In a one-sided EWMA control chart, the $\mathrm{ARL}_{1}$ values are always lower than the $\mathrm{ARL}_{1}$ values of a two-sided control chart. This is because the LCL of the one-sided control chart is larger than that of the two-sided control chart. Therefore, in the event of a shift in the process, the one-sided control chart will detect the deviation faster, as illustrated in Figure 8. Moreover, because the one-sided control chart has only one control limit, it monitors the process only on one side, and its $\mathrm{ARL}_{1}$ chart has a uniform behavior. This is unlike the $\mathrm{ARL}_{1}$ chart of the two-sided control chart, which is biased.

\section{SIMULATION STUDY}

To show the performance of the control charts, two examples are presented here. A two-sided control chart is used in the first one, and the second one is about a onesided control chart.

\section{1. Example 1 A simulation study is conducted} to show the performance of the proposed control charts. First, 20 sample points are generated while $\theta_{0}=1$. Then, 30 sample points are generated while the scale parameter

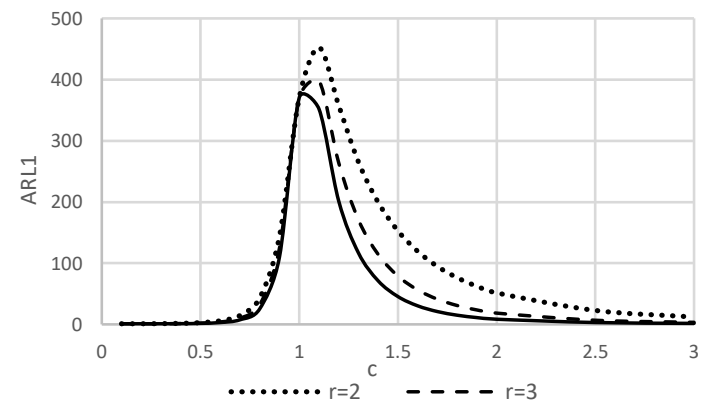

Figure 2. ARL1 of the two-sided control charts for different values of $r$

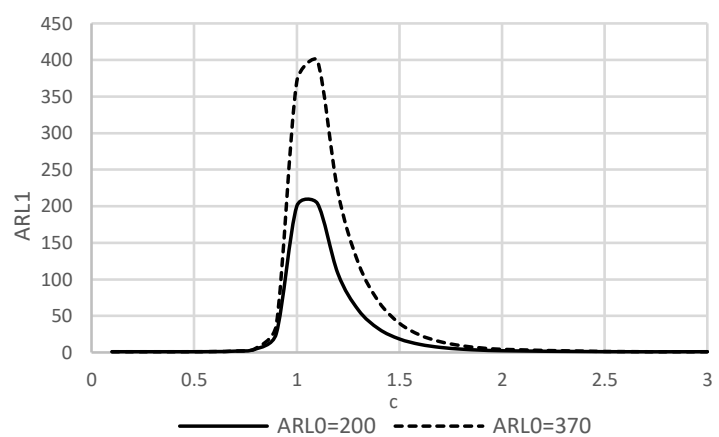

Figure 3. $A R L_{1}$ of the two-sided control charts for different values of $A R L_{0}$

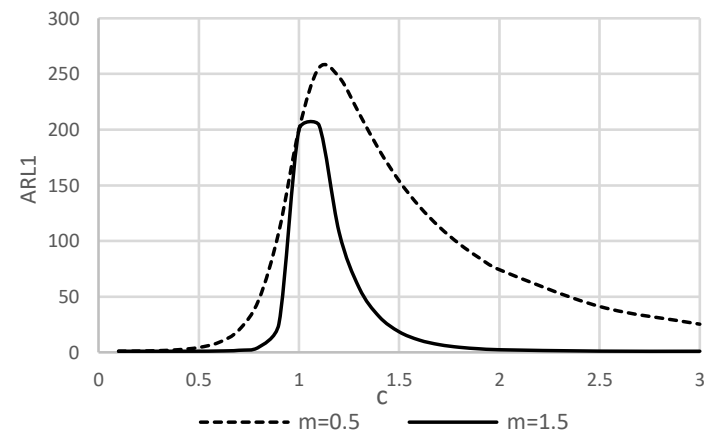

Figure 4. ARL $\mathrm{L}_{1}$ of the two-sided control charts for different values of $m$

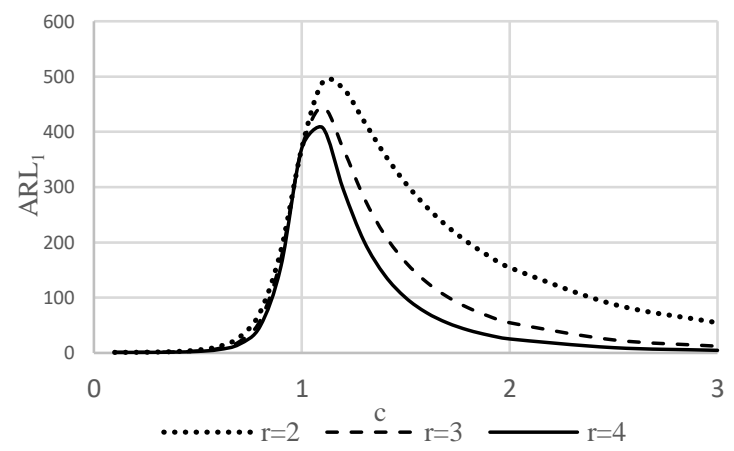

Figure 5. ARL $\mathrm{A}_{1}$ of the two-sided control charts for different values of $c$

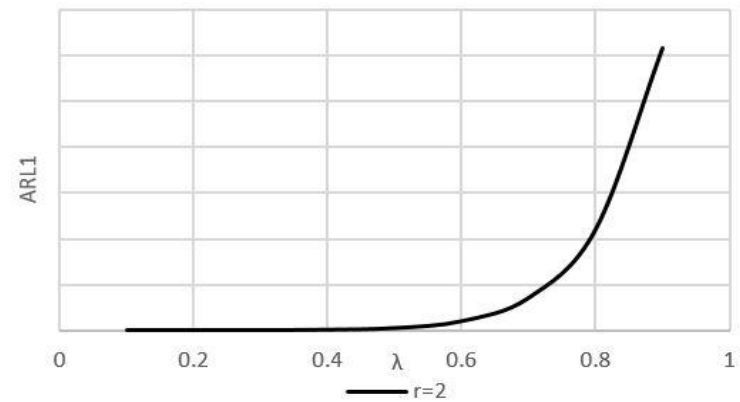

Figure 6. $A R L_{1}$ of the two-sided control charts for different values of $\lambda$ 


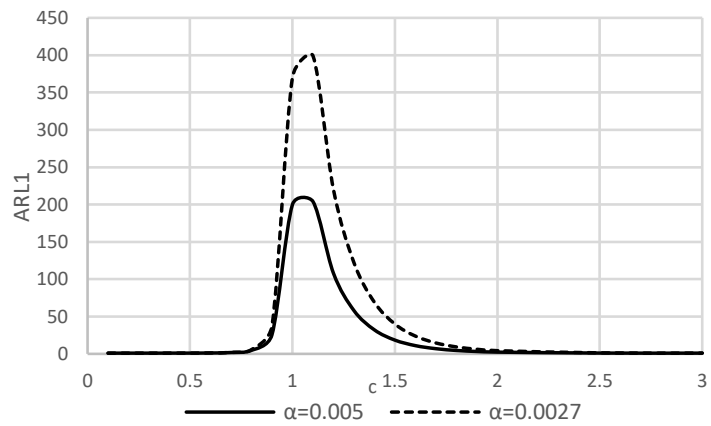

Figure 7. ARL1 of the two-sided control charts for different values of $\alpha$

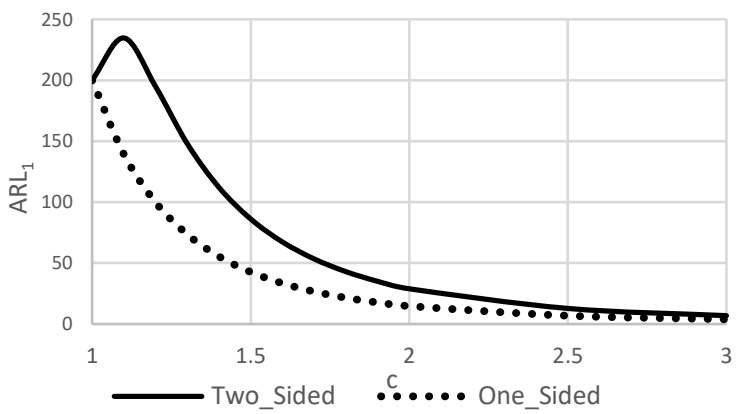

Figure 8. Comparison of the ARLs for one-sided and twosided control charts

shifts from $\theta_{0}=1$ to $\theta=0.7$. The other inputs of the control charts include $A R L_{0}=370, m=2, n=5, r=$ 3 , and $\lambda=0.2$. Table 3 presents the limits of the control charts. The values of the control statistic $Q_{i}$ and the failure times are also provided in Table 4 . The values of $\mathrm{Q}_{\mathrm{i}}$ are plotted on the control chart in Figure 9. The figure clearly shows the changes in sample 26 .

\section{2. Example 2 In this example, First, 15 sample} points are generated while $\theta_{0}=1$. Then, 25 sample points are generated while the scale parameter shifts from $\theta_{0}=1$ to $\theta=1.5$. The other inputs of the control charts include $A R L_{0}=200, m=1.5, n=5, r=3$, and $\lambda=$ 0.3 . Table 3 shows the limits of the control charts. The values of $\mathrm{Q}_{i}$ are also plotted on the control chart in Figure 10. The changes in sample 21 are evident in this figure.

\section{CASE STUDY}

As a case study, the real data of a car manufacturer in Korea are used to design control charts [10]. The data are about the operational time of a part of the machine until failure occurs in a period of one month.

The data follow the Weibull distribution with the shape parameter $m=2.5$ and the scale parameter $\theta_{0}=1$. The assumptions are $\mathrm{ARL}_{0}=370, r=3$, and $\lambda=0.4$. The values of $\mathrm{V}_{\mathrm{i}}$ and $\mathrm{Q}_{\mathrm{i}}$ are shown in Table 5 .
TABLE 3. The control limits of the control charts

\begin{tabular}{|c|c|c|c|c|c|c|c|}
\hline \multirow{2}{*}{$\begin{array}{l}\text { Two- } \\
\text { sided }\end{array}$} & \multicolumn{4}{|c|}{$\mathrm{ARL} 0=370$} & \multicolumn{2}{|c|}{$m=2$} & \multirow[b]{2}{*}{6} \\
\hline & $\mathrm{r}$ & 1 & 2 & 3 & 4 & 5 & \\
\hline \multirow{2}{*}{$\lambda=0.2$} & UCL & 2.5 & 4.3 & 6.02 & 7.63 & 9.21 & 10.7 \\
\hline & LCL & 0 & 0.7 & 1.61 & 2.54 & 3.51 & 4.5 \\
\hline \multirow{2}{*}{$\begin{array}{l}\text { Two- } \\
\text { sided }\end{array}$} & \multicolumn{4}{|c|}{$\mathrm{ARL} 0=370$} & \multicolumn{2}{|c|}{$m=2.5$} & \\
\hline & $\mathrm{r}$ & 1 & 2 & 3 & 4 & 5 & 6 \\
\hline \multirow{2}{*}{$\lambda=0.4$} & UCL & 3.3 & 5.5 & 7.54 & 9.43 & 11.2 & 13.1 \\
\hline & LCL & - & - & 0.54 & 1.34 & 2.21 & 3.13 \\
\hline \multirow{2}{*}{$\begin{array}{l}\text { One- } \\
\text { sided }\end{array}$} & & \multicolumn{3}{|c|}{$\mathrm{ARL} 0=200$} & \multicolumn{2}{|c|}{$m=1.5$} & \\
\hline & $\mathrm{r}$ & 1 & 2 & 3 & 4 & 5 & 6 \\
\hline$\lambda=0.3$ & LCL & - & 0.5 & 1.31 & 2.14 & 3.01 & 3.91 \\
\hline
\end{tabular}

TABLE 4. The simulated data and the statistical values

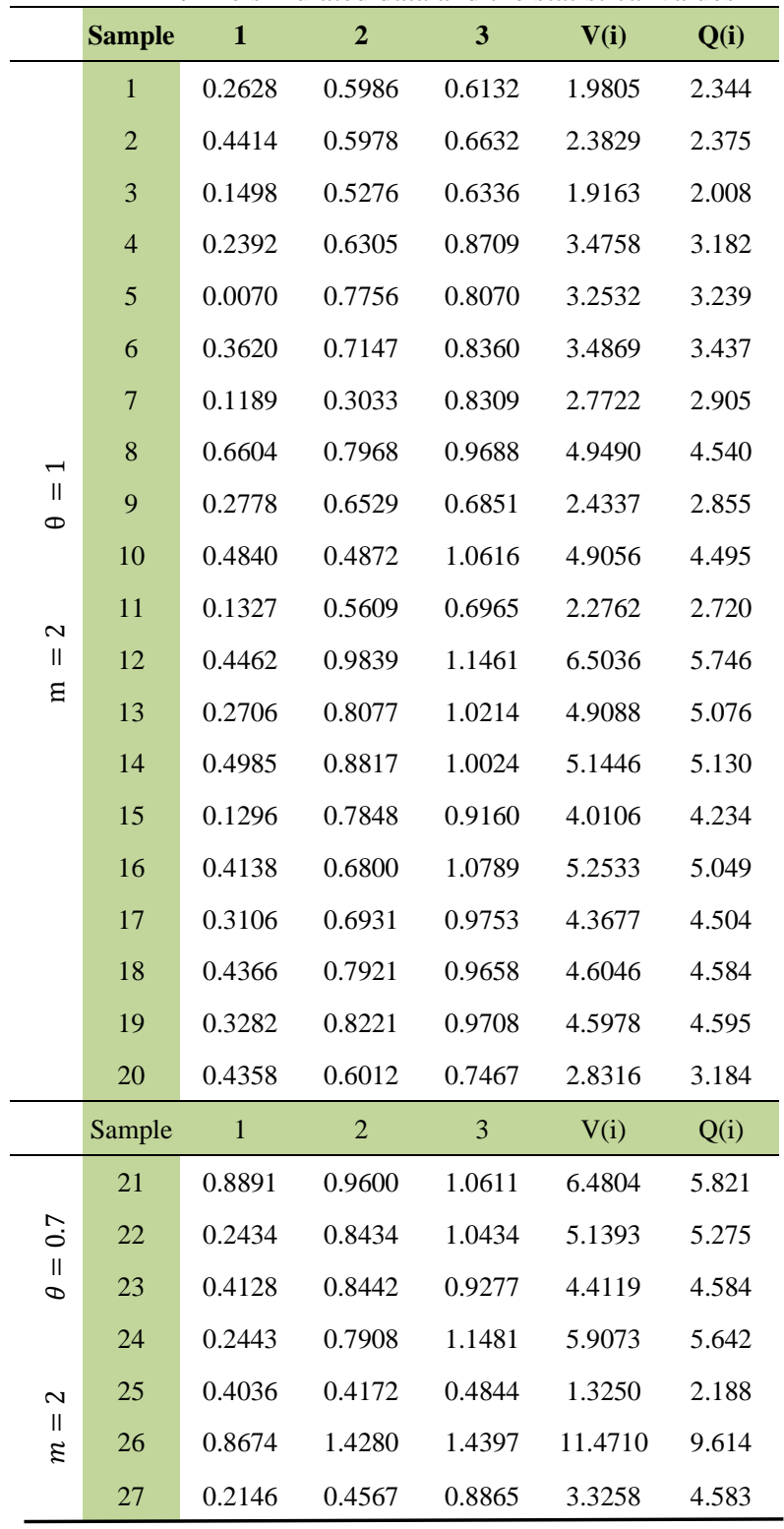




\begin{tabular}{lllllll}
\hline 28 & 0.5578 & 1.0281 & 1.4927 & 10.2532 & 9.119 \\
29 & 0.6363 & 1.0198 & 1.2363 & 7.6773 & 7.965 \\
30 & 0.4170 & 0.5209 & 1.0497 & 4.7758 & 5.413 \\
31 & 1.4443 & 0.9263 & 1.2582 & 9.7957 & 8.919 \\
32 & 0.5874 & 0.8391 & 0.9157 & 4.5383 & 5.414 \\
33 & 0.3551 & 0.8920 & 1.2037 & 6.7077 & 6.449 \\
34 & 0.1578 & 0.7775 & 1.3584 & 7.8497 & 7.569 \\
35 & 1.0975 & 1.1039 & 1.1934 & 8.5247 & 8.333 \\
\hline 36 & 0.6039 & 1.2403 & 1.6447 & 12.757 & 11.87 \\
37 & 0.9551 & 1.0658 & 1.8941 & 16.317 & 15.42 \\
\hline 38 & 0.4016 & 0.6704 & 0.9525 & 4.231 & 6.479 \\
39 & 1.3108 & 1.3249 & 1.4853 & 12.848 & 11.57 \\
\hline 40 & 0.4727 & 0.8110 & 0.8543 & 3.909 & 5.442 \\
\hline 41 & 0.1710 & 0.9366 & 1.8650 & 14.443 & 12.64 \\
\hline 42 & 0.3562 & 0.6444 & 0.8107 & 3.200 & 5.088 \\
\hline 43 & 0.4010 & 0.4344 & 1.5475 & 9.592 & 8.691 \\
\hline 44 & 0.5393 & 0.6582 & 0.9561 & 4.413 & 5.269 \\
\hline 45 & 0.6136 & 1.1168 & 1.2072 & 7.633 & 7.160 \\
\hline 46 & 0.9505 & 1.6125 & 1.8332 & 17.291 & 15.27 \\
\hline 47 & 1.0844 & 1.0919 & 1.2606 & 9.080 & 10.322 \\
48 & 0.6196 & 0.7171 & 1.2194 & 6.821 & 7.522 \\
\hline 49 & 0.1140 & 0.9953 & 1.2717 & 7.450 & 7.468 \\
50 & 0.4324 & 0.4668 & 0.5071 & 1.497 & 2.691 \\
\hline & & & & & \\
\hline
\end{tabular}

The process is monitored with the EWMA control chart. The control limits are shown in Table 3. The values of $\mathrm{Q}_{\mathrm{i}}$ are plotted on the control chart (Figure 11).

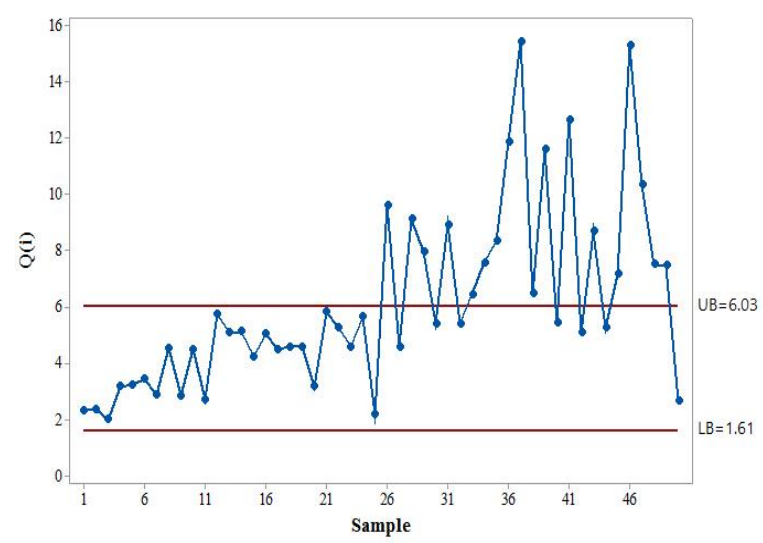

Figure 9. The proposed control chart for the simulated data while the process improves

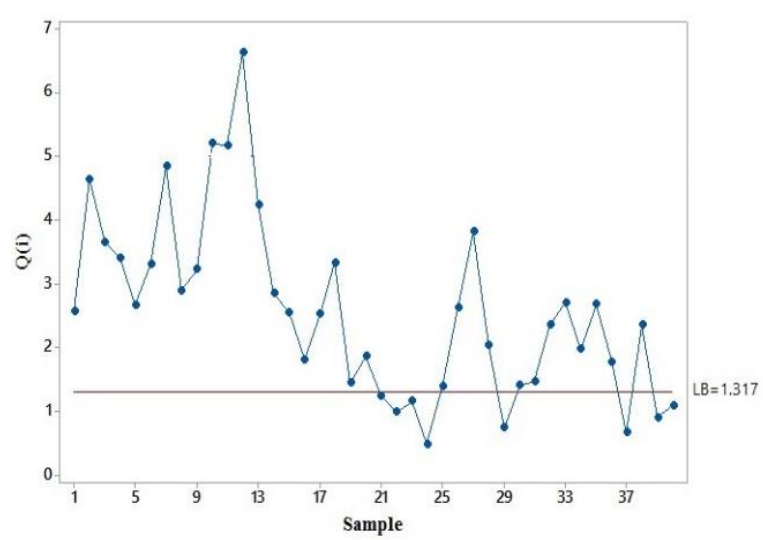

Figure 10. The proposed control chart for the simulated data while the process deteriorates

TABLE 5. The simulated data and the statistical values

\begin{tabular}{lccccccc}
\hline Sample & $\mathbf{1}$ & $\mathbf{2}$ & $\mathbf{3}$ & $\mathbf{4}$ & $\mathbf{5}$ & $\mathbf{6}$ & $\mathbf{7}$ \\
\hline V(i) & 8.26 & 9.68 & 3.22 & 3.75 & 5.14 & 1.30 & 2.97 \\
Q(i) & 7.14 & 8.92 & 4.93 & 4.10 & 4.83 & 2.36 & 2.79 \\
Sample & 8 & 9 & 10 & 11 & 12 & 13 & 14 \\
V(i) & 5.92 & 3.42 & 4.71 & 4.59 & 7.99 & 9.76 & 5.39 \\
Q(i) & 4.98 & 3.88 & 4.46 & 4.55 & 6.96 & 8.92 & 6.45 \\
Sample & 15 & 16 & 17 & 18 & 19 & 20 & 21 \\
V(i) & 2.40 & 3.80 & 3.86 & 1.65 & 1.10 & 3.11 & 4.23 \\
Q(i) & 3.61 & 3.75 & 3.82 & 2.30 & 1.46 & 2.62 & 3.75 \\
Sample & 22 & 23 & 24 & 25 & 26 & 27 & 28 \\
V(i) & 3.12 & 7.10 & 5.56 & 6.44 & 4.18 & 3.44 & 7.26 \\
Q(i) & 3.31 & 5.96 & 5.68 & 6.21 & 4.79 & 3.85 & 6.24 \\
Sample & 29 & 30 & 31 & 32 & 33 & 34 & 35 \\
V(i) & 4.66 & 0.69 & 1.93 & 2.96 & 5.09 & 5.30 & 10.22 \\
Q(i) & 5.13 & 2.02 & 1.96 & 2.66 & 4.36 & 5.02 & 8.66 \\
Sample & 36 & 37 & 38 & 39 & 40 & 41 & 42 \\
V(i) & 4.68 & 3.21 & 2.68 & 4.64 & 10.51 & 2.52 & 1.11 \\
Q(i) & 5.88 & 4.01 & 3.08 & 4.17 & 8.61 & 4.35 & 2.08 \\
\hline Sample & 43 & 44 & 45 & 46 & 47 & 48 & 49 \\
V(i) & 4.05 & 8.87 & 3.25 & 2.09 & 5.23 & 1.36 & 4.59 \\
Q(i) & 3.46 & 7.25 & 4.45 & 2.79 & 4.50 & 2.30 & 3.90 \\
Sample & 50 & & & & & & \\
V(i) & 3.17 & & & & & & \\
Q(i) & 3.39 & & & & & & \\
\hline & & & & & & & \\
\hline
\end{tabular}




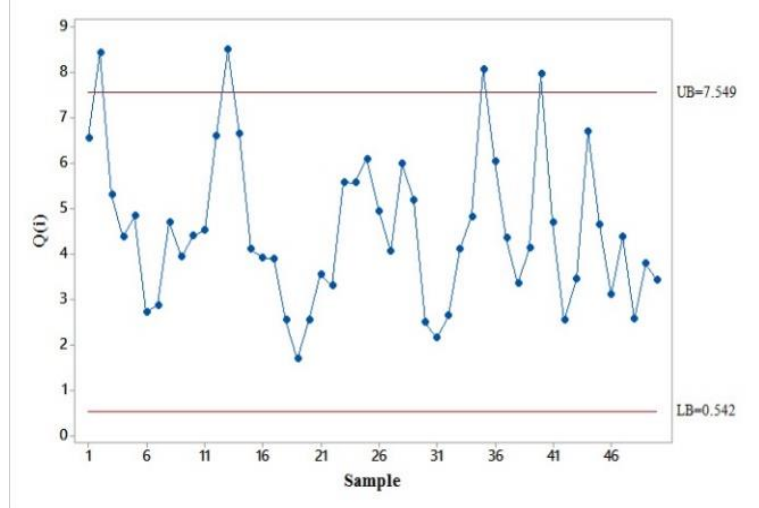

Figure 11. The control chart proposed for real data

The EWMA chart shows that the process is sometimes out of control, and corrective action is needed immediately.

\section{CONCLUSION}

In this study, one-sided and two-sided EWMA control charts were designed under Type II censoring life tests. As a quality characteristic of products, it was assumed that lifetime would follow the Weibull distribution with a fixed shape parameter and a variable scale parameter. First, the relationships of control limits, $\beta$ error and $\mathrm{ARL}_{1}$ were presented. Then, the control limits were calculated for different parameters while $\mathrm{ARL}_{1}$ were used to evaluate the performance of the control charts. The $\mathrm{ARL}_{1}$ values of those parameters were also obtained and presented in tables. As the numerical analyses showed, the $\mathrm{ARL}_{1}$ values would decrease with an increase in $r$ and $m$ and increase as the $\mathrm{ARL}_{0}$ values increased. Moreover, as the $r$ parameter increased, the ability of the control chart to detect out-of-control states also increased. Similarly, the $\mathrm{ARL}_{1}$ values were found to rise with an increase in the value of $\lambda$. In the two-sided control chart, the $\mathrm{ARL}_{1}$ curve varied up and down uniformly. The examination of the $\mathrm{ARL}_{1}$ curves and values of the charts proved that the one-sided control chart outperforms the two-sided control chart in detecting shifts. Compared to the Shewhart type control chart, the proposed control chart has a significantly better capability of detecting outof-control states in production processes to avoid producing low-quality items. Using the proposed control chart, it is possible to have continual improvement in lifetime as an important quality characteristic of products. The mangers of manufacturing companies can also significantly reduce their costs and improve the competitiveness of their businesses. Moreover, since the EWMA control chart is designed based on efficient failure censoring life testing, it can decrease the cost of the life testing involved in the application of control charts. Designing EWMA control charts for hybrid censoring life tests and unbiased EWMA control charts under failure censoring is a recommendation for future studies.

\section{REFERENCES}

1. Tsekouras, K., Dimara, E. and Skuras, D., "Adoption of a quality assurance scheme and its effect on firm performance: A study of greek firms implementing iso 9000", Total quality management, Vol. 13, No. 6, (2002), 827-841, doi: 10.1080/0954412022000010163.

2. Siraj, I. and Bharti, P.S., "Reliability analysis of a $3 \mathrm{~d}$ printing process", Procedia Computer Science, Vol. 173, (2020), 191200, doi: 10.1002/j.1538-7305.1926.tb00125.x.

3. Montgomery, D.C., "Introduction to statistical quality control, John Wiley \& Sons, (2020).

4. Roberts, S., "Control chart tests based on geometric moving averages", Technometrics, Vol. 42, No. 1, (2000), 97-101, doi: 10.1080/00401706.2000.10485986.

5. Barlow, R.E. and Proschan, F., Statistical theory of reliability and life testing: Probability models. 1975, Florida State Univ Tallahassee.

6. Bayati, N. and Kabiri Naeini, M., "Pattern recognition in control chart using neural network based on a new statistical feature", International Journal of Engineering, Vol. 30, No. 9, (2017), 1372-1380, doi: 10.5829/idosi.ije.2017.30.09c.10.

7. Fattahzadeh, M. and Saghaei, A., "A statistical method for sequential images-based process monitoring", International Journal of Engineering, Vol. 33, No. 7, (2020), 1285-1292, doi: 10.5829/IJE.2020.33.07A.15.

8. Rasay, H., Fallahnezhad, M. and ZareMehrjardi, Y., "Application of multivariate control charts for condition based maintenance", International Journal of Engineering, Vol. 31, No. 4, (2018), 597-604, doi: 10.5829/ije.2018.31.04a.11.

9. Sadeghi, H., Owlia, M.S., Doroudyan, M.H. and Amiri, A., "Monitoring financial processes with arma-garch model based on shewhart control chart (case study: Tehran stock exchange)", International Journal of Engineering, Vol. 30, No. 2, (2017), 270-280, doi: 10.5829/idosi.ije.2017.30.02b.14.

10. Khan, N., Aslam, M., Raza, S.M.M. and Jun, C.H., "A new variable control chart under failure-censored reliability tests for weibull distribution", Quality and Reliability Engineering International, Vol. 35, No. 2, (2019), 572-581, doi: 10.1002/qre.2422.

11. Adeoti, O.A. and Ogundipe, P., "A control chart for the generalized exponential distribution under time truncated life test", Life Cycle Reliability and Safety Engineering, Vol. 10, No. 1, (2021), 53-59, doi: 10.1007/s41872-020-00146-9.

12. Balamurali, S. and Jeyadurga, P., "An attribute np control chart for monitoring mean life using multiple deferred state sampling based on truncated life tests", International Journal of Reliability, Quality and Safety Engineering, Vol. 26, No. 01, (2019), 1950004, doi: 10.1142/S0218539319500049.

13. Aslam, M., Raza, M.A., Sherwani, R.A.K., Farooq, M., Jeong, J.Y. and Jun, C.-H., "A mixed control chart for monitoring failure times under accelerated hybrid censoring", Journal of Applied Statistics, Vol. 48, No. 1, (2021), 138-153, doi: 10.1080/02664763.2020.1713060.

14. Gadde, S.R., Fulment, A. and Josephat, P., "Attribute control charts for the dagum distribution under truncated life tests", Life Cycle Reliability and Safety Engineering, Vol. 8, No. 4, (2019), 329-335, doi: 10.1007/s41872-019-00090-3. 
15. Xu, S. and Jeske, D.R., "Weighted ewma charts for monitoring type i censored weibull lifetimes", Journal of Quality Technology, Vol. 50, No. 2, (2018), 220-230, doi: 10.1080/00224065.2018.1436830.

16. Faraz, A., Saniga, E.M. and Heuchenne, C., "Shewhart control charts for monitoring reliability with weibull lifetimes", Quality and Reliability Engineering International, Vol. 31, No. 8, (2015), 1565-1574, doi: 10.1002/qre.1692.
17. Rasay, H. and Arshad, H., "Designing variable control charts under failure censoring reliability tests with replacement", Transactions of the Institute of Measurement and Control, Vol. 42, No. 15, (2020), 3002-3011, doi: 10.1177/0142331220938206.

18. Jun, C.-H., Lee, H., Lee, S.-H. and Balamurali, S., "A variables repetitive group sampling plan under failure-censored reliability tests for weibull distribution", Journal of Applied Statistics, Vol. 37, No. 3, (2010), 453-460, doi: 10.1080/02664760802715914.

طول عمر محصولات يكى از مهمترين مشخصههاى كيفى مد نظر در توليد مىباشد. از اين رو توليدكندكًان به دنبال توليد محصولات با قابليت اطمينان بالا هستند. دادههاى طول عمر به علت اينكه اندازهكيرى آنها صرف زمان و هزينه بالايى مىباشد، طراحى يكى نمودار كتترل را مشكل مى كنند. براى حل اين مشكل از آزمونهاى طول عمر استفاده

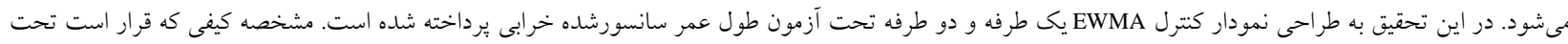

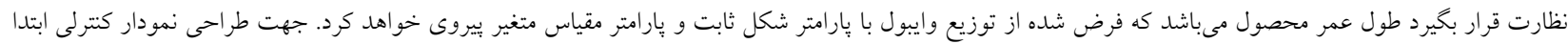

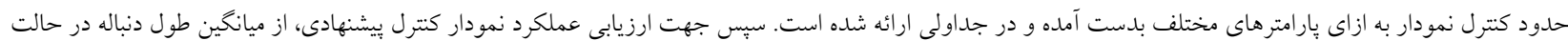

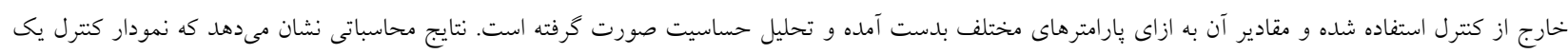

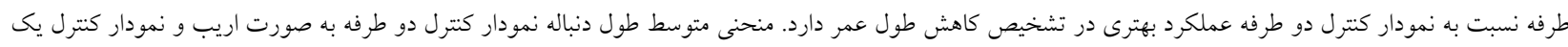

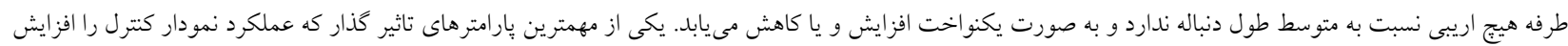

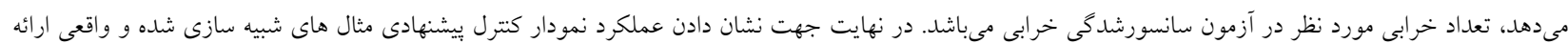

